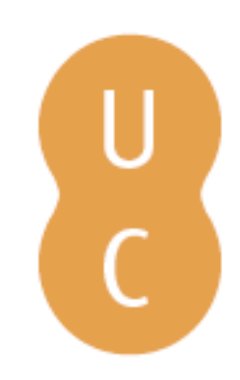

\title{
nombalina
}

\section{Metodologia para análise de conchostráceos em microscópia óptica oriundos de folhetos betuminosos}

\author{
Autor(es): $\quad$ Souza, A. F.; Carvalho, I. S.; Garcia, K. L. \\ Publicado por: Centro de Estudos Clássicos e Humanísticos da Universidade de \\ URL \\ persistente: URI:http://hdl.handle.net/10316.2/31428 \\ DOI: $\quad$ DOI:http://dx.doi.org/10.14195/978-989-26-0534-0_21 \\ Accessed : $\quad$ 26-Apr-2023 13:21:11
}

A navegação consulta e descarregamento dos títulos inseridos nas Bibliotecas Digitais UC Digitalis, UC Pombalina e UC Impactum, pressupõem a aceitação plena e sem reservas dos Termos e Condições de Uso destas Bibliotecas Digitais, disponíveis em https://digitalis.uc.pt/pt-pt/termos.

Conforme exposto nos referidos Termos e Condições de Uso, o descarregamento de títulos de acesso restrito requer uma licença válida de autorização devendo o utilizador aceder ao(s) documento(s) a partir de um endereço de IP da instituição detentora da supramencionada licença.

Ao utilizador é apenas permitido o descarregamento para uso pessoal, pelo que o emprego do(s) título(s) descarregado(s) para outro fim, designadamente comercial, carece de autorização do respetivo autor ou editor da obra.

Na medida em que todas as obras da UC Digitalis se encontram protegidas pelo Código do Direito de Autor e Direitos Conexos e demais legislação aplicável, toda a cópia, parcial ou total, deste documento, nos casos em que é legalmente admitida, deverá conter ou fazer-se acompanhar por este aviso. 



\title{
METODOLOGIA PARA ANÁLISE DE CONCHOSTRÁCEOS EM MICROSCÓPIA ÓPTICA ORIUNDOS DE FOLHELOS BETUMINOSOS
}

\author{
METHODOLOGY TO CONCHOSTRACAN \\ ANALYSIS IN OPTICAL MICROSCOPY \\ FROM BITUMINOUS SHALE
}

A. F. Souza ${ }^{1,2}$ I. S. Carvalho ${ }^{1} \&$ K. L. Garcia ${ }^{1,2}$

\begin{abstract}
Resumo - Novos procedimentos metodológicos para a identificação de conchostráceos foram realizados em amostras de folhelhos betuminosos, oriundas da Bacia de Sergipe-Alagoas (Formação Maceió, Cretáceo Inferior, Brasil), processadas para recuperação de matéria orgânica, nas quais há a presença de uma fauna monoespecífica de conchostráceos (Cyzicus pricei) e palinomorfos. A análise das lâminas em microscopia ótica permitiu identificar e reconhecer os fragmentos de conchostráceos, com os padróes de suas respectivas linhas de crescimento, e ornamentaçôes variadas, não perceptíveis em fósseis submetidos à iluminação direta.
\end{abstract}

Palavras-chave - Conchostráceos; Formação Maceió; Bacia de Sergipe-Alagoas; Brasil

Abstract - New methodological procedures for identifying conchostracans were performed on samples of bituminous shales derived from the Sergipe-Alagoas Basin (Maceió Formation, Early Cretaceous), processed for recovery of organic matter, where there is the presence of a monospecific fauna of conchostracans (Cyzicus pricei) and palynomorphs. The analysis of slides using the optical microscopy allows to identify and to recognize the fragments of conchostracans with the standards of their respective growth lines, and varied ornamentation, which could not be possible to observe in fossils submitted to direct light.

Keywords - Conchostracans; Maceió Formation; Sergipe-Alagoas Basin; Brazil

1 Dep. de Geologia, Universidade Federal do Rio de Janeiro, Rio de Janeiro, Brasil; alicefsouza@gmail.com; ismar@geologia.ufrj.br

2 Diretoria Nacional de Pós Graduação, Universidade Estácio de Sá, Rio de Janeiro, Brasil; alicefsouza@ gmail.com; karinalg1000@yahoo.com.br 


\section{1 - Introdução}

Os conchostráceos são crustáceos que possuem o corpo inteiramente protegido por uma carapaça quitinosa, que geralmente está impregnada por carbonato de cálcio. Pelo seu tamanho diminuto, têm sido identificados em testemunhos de sondagem, podendo fornecer informaçôes sobre o fóssil e o ambiente em que se deu a deposição dos sedimentos. Essas características tornam os conchostráceos bons indicadores ambientais, e a identificação das espécies a partir de fragmentos de carapaça em lâminas amplia sua aplicação paleoambiental e bioestratigráfica.

Seus ovos podem ser submetidos a longos períodos de seca, podendo se dispersar através do vento e da água. Quando o ambiente volta a ser favorável, os ovos eclodem e o organismo passa por uma fase larvar até chegar à fase adulta. É nessa fase que se forma a carapaça e o organismo começa a viver sobre o substrato dos corpos aquáticos (CARVALHO, 1993).

Os conchostráceos, como todos os artrópodes, possuem uma cutícula, exoesqueleto, que recobre toda a superfície do corpo e apêndices. Esta carapaça está presa ao corpo do organismo apenas por um simples músculo, o que faz com que periodicamente ela sofra um acréscimo, enquanto o animal troca todo seu exoesqueleto quitinoso. Possuem zoneamentos de crescimento, separados por linhas, denominadas como linhas de crescimento, cuja função é ampliar o tamanho da carapaça para acompanhar o crescimento do animal, refletindo, portanto, as fases de desenvolvimento desses crustáceos. As características apresentadas por essas linhas constituem-se no principal foco do estudo da paleobiologia desse grupo de organismos.

Os fósseis oriundos da Bacia de Sergipe-Alagoas (Formação Maceió, Cretáceo Inferior), estão presentes nos níveis de folhelhos betuminosos, onde ocorre uma fauna monoespecífica de conchostráceos (Cyzicus pricei). Todos os exemplares pertencem à mesma espécie, pois apresentam o mesmo padrão de ornamentação microalveolar carenado, característico da espécie Cyzicus pricei. Este padrão caracteriza-se por apresentar os minúsculos alvéolos impregnados por carbonato de cálcio.

Exemplares com diferentes tamanhos indicam que o estágio embrionário de cada ovo em estado de latência era diferente quando ocorreu a eclosão.

\section{2 - Metodologia}

O desenvolvimento de uma metodologia para a recuperação de fragmentos de conchostráceos possibilita sua identificação através da observação ao microscópio óptico da ornamentação intra-alveolar presente em sua carapaça.

A metodologia foi desenvolvida com amostras de folhelhos betuminosos, oriundos da Praia de Japaratinga (Japaratinga, Alagoas) da Formação Maceió, Bacia de Sergipe-Alagoas, Brasil, através de processamento para recuperação de matéria orgânica, seguindo a metodologia de OLIVEIRA et al. (2006).

Foram preparadas lâminas, tomando como base o processamento de amostras para análise palinológica. $\mathrm{O}$ material sofreu uma sequência de ataques químicos, a fim de se obter um resíduo isento de material inorgânico e húmico, contendo apenas material orgânico com a presença de conchostráceos. O processo consiste das seguintes etapas: 
a) Coloca-se $40 \mathrm{~g}$ de sedimento em um béquer de vidro de $250 \mathrm{ml}$ e, logo em seguida, inicia-se a acidificação com ácido clorídrico concentrado $(\mathrm{HCl})$ a $32 \%$ para se eliminar o carbonato.

b) Deixa-se em repouso por $2 \mathrm{~h}$. Após esse tempo, acrescenta-se água destilada para iniciar o processo de neutralização e espera-se o material decantar. Com uma peneira de malha de poliéster, peneira-se a solução ácida, e retorna-se o material retido na mesma para o béquer. Faz-se esse procedimento até que a água esteja neutralizada.

c) O mesmo procedimento é realizado com o ácido fluorídrico concentrado (HF) a 40\%, visando à eliminação de silicatos. Neste, a amostra permanece por $12 \mathrm{~h}$ em repouso. Após a neutralizaçáo completa do mesmo, a amostra é acidificada com $\mathrm{HCl}$ a $10 \%$ por $3 \mathrm{~h}$, para a eliminação do fluorsilicato, formado durante o processo anterior, e repete-se o procedimento anterior.

d) No intuito de eliminar a fração mais grossa do resíduo, e consequentemente proporcionar a concentração dos fragmentos de conchostráceos, faz-se uso de peneira com malha de $200 \mu \mathrm{m}$.

e) Em seguida, o material sofre ataque com ácido nítrico concentrado $\left(\mathrm{HNO}_{3}\right)$, juntamente com clorato de potássio $\left(\mathrm{KClO}_{3}\right)$, com duração de $15 \mathrm{~min}$.

f) Posteriormente é adicionado cloreto de zinco por $20 \mathrm{~min}$, objetivando a separação do material pesado do material mais leve (separação por flotação). Após a separação por flotação, seguida da decantação, adiciona-se ácido $\mathrm{HCl}$ diluído a $10 \%$.

g) O material é entấo peneirado com malha de $10 \mu \mathrm{m}$, e após a lavagem com água destilada, são preparadas as lâminas usando-se uma chapa aquecedora à temperatura de aproximadamente $30^{\circ}$ e entellan para a colagem da lamínula.

As lâminas preparadas tomam como base o processamento de amostras para análise de palinofácies e fácies orgânica com o intuito de obter amostras com conchostráceos, seguindo como base a metodologia de OLIVEIRA et al. (2006).

O processo consiste das seguintes etapas:

a) Com béqueres de vidro de $250 \mathrm{ml}$, acrescenta-se $40 \mathrm{~g}$ de sedimento e, logo em seguida, inicia-se a acidificação com ácido clorídrico $(\mathrm{HCl})$ a $37 \%$.

b) Deixa-se em repouso por $18 \mathrm{~h}$. Após esse tempo, acrescenta-se água destilada para iniciar o processo de neutralização e espera-se o material decantar. Peneira-se a solução ácida, e retorna-se o material retido na mesma para o béquer. Faz-se esse procedimento até que a água esteja neutralizada.

c) O mesmo procedimento é realizado com o ácido fluorídrico (HF) a 40\%. Neste, a amostra permanece por $24 \mathrm{~h}$ em repouso. Após a neutralização completa do mesmo, a amostra é acidificada com $\mathrm{HCl}$ a $10 \%$ por $3 \mathrm{~h}$ e, novamente, utiliza-se o mesmo procedimento anterior.

d) Com o material neutralizado e diluído, passa-se o mesmo para um tubo de ensaio de $250 \mathrm{ml}$, centrifuga-se por $3 \mathrm{~min}$ com velocidade de $1.500 \mathrm{rpm}$. Usa-se a peneira para verter o líquido sobrenadante, retornando o material retido na peneira novamente para o tubo de ensaio.

e) Acrescenta-se cloreto de zinco $\left(\mathrm{ZnCl}_{2}\right)$ no tubo de ensaio e agita-se. Usa-se a centrífuga por $30 \mathrm{~min}$ ou deixa-se o material em repouso por $12 \mathrm{~h}$, para que a matéria orgânica seja separada do material inorgânico.

f) Com a matéria orgânica separada passa-se para outro tubo de ensaio, acrescenta-se algumas gotas de $\mathrm{HCl}$ a 10\%, agita-se bem e coloca-se o tubo na centrífuga por 3 min a velocidade de $1.500 \mathrm{rpm}$; em seguida, verte-se o líquido sobrenadante para a peneira, retornando o material retido novamente para o tubo de ensaio. 


\section{3 - Resultados}

A utilização deste método possibilitou a recuperação de fragmentos de carapaças de conchostráceos, de forma indireta, através do método de obtenção de palinofácies, fácies orgânicas e palinomorfos.

A análise das lâminas em microscopia óptica permitiu identificar e reconhecer fragmentos de conchostráceos, com suas respectivas linhas de crescimento e ornamentaçóes intra-alveolar (Fig. 1). Os fragmentos de conchostráceos permitiram a observação em luz transmitida de ornamentaçốes variadas, não reconhecidas em fósseis submetidos à iluminação direta (Figs. 2 e 3). Tal proposição amplia os procedimentos metodológicos para a identificação de conchostráceos, possibilitando interpretaçôes paleoambientais e possíveis correlações bioestratigráficas.

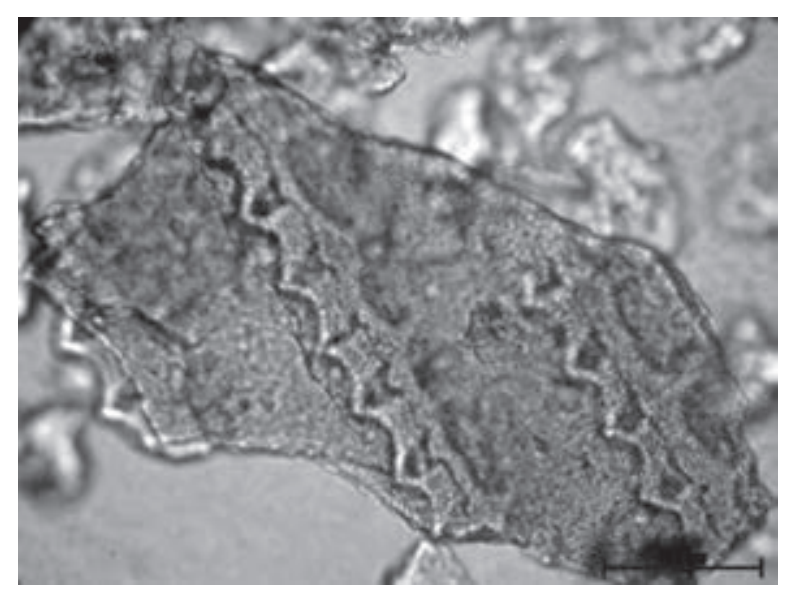

Fig. 1 - Ornamentação microalveolar característica da espécie Cyzicus pricei.

\section{$4-$ Conclusóes}

A recuperação de fragmentos de carapaças de conchostráceos pelo método de obtenção de palinofácies é possível com a preparação de lâminas, tomando como base o processamento de amostras para análise de palinofácies e fácies orgânica.

As lâminas preparadas para obtenção de fragmentos de conchostráceos, com preservação de suas linhas de crescimento e ornamentaçôes intra-alveolar, tomando como base o processamento de amostras para análise palinológica, mostrou ser eficiente para identificação desses microorganismos e suas estruturas em bom estado de preservação.

Agradecimentos - À João Graciano Medonça Filho, por disponibilizar o laboratório de Palinofácies e Fácies Orgânicas (LAFO) para preparação das amostras e a toda sua equipe, em especial, Antônio Donizeti de Oliveira, Joalice de Oliveira Medonça e Jaqueline Torres de Souza pela colaboração na preparação e confecção das lâminas e pela análise e fotografia das amostras. Este estudo contou com o apoio da FAPERJ e CNPq. 


\section{Referências}

CARVAlHO, I. S. (1993) - Os Conchostráceos Fósseis das Bacias Interiores do Nordeste do Brasil. Programa de Pós-graduação em Geociências, Universidade Federal do Rio de Janeiro, Tese de Doutorado, 310 p.

OLIVEIRA, A.D., MEDONÇA-FIlHO, J. G., SANT’ANNA, A. J., SOUZA, J. T., FREITAS, A. G. \& MENEZES, T. R. (2006) - Inovação no processamento químico para isolamento da matéria orgânica sedimentar. In: Congresso Brasileiro de Geologia, 43, Aracaju, 2006. Boletim de Resumos, Aracaju, Sociedade Brasileira de Geologia, p. 324.
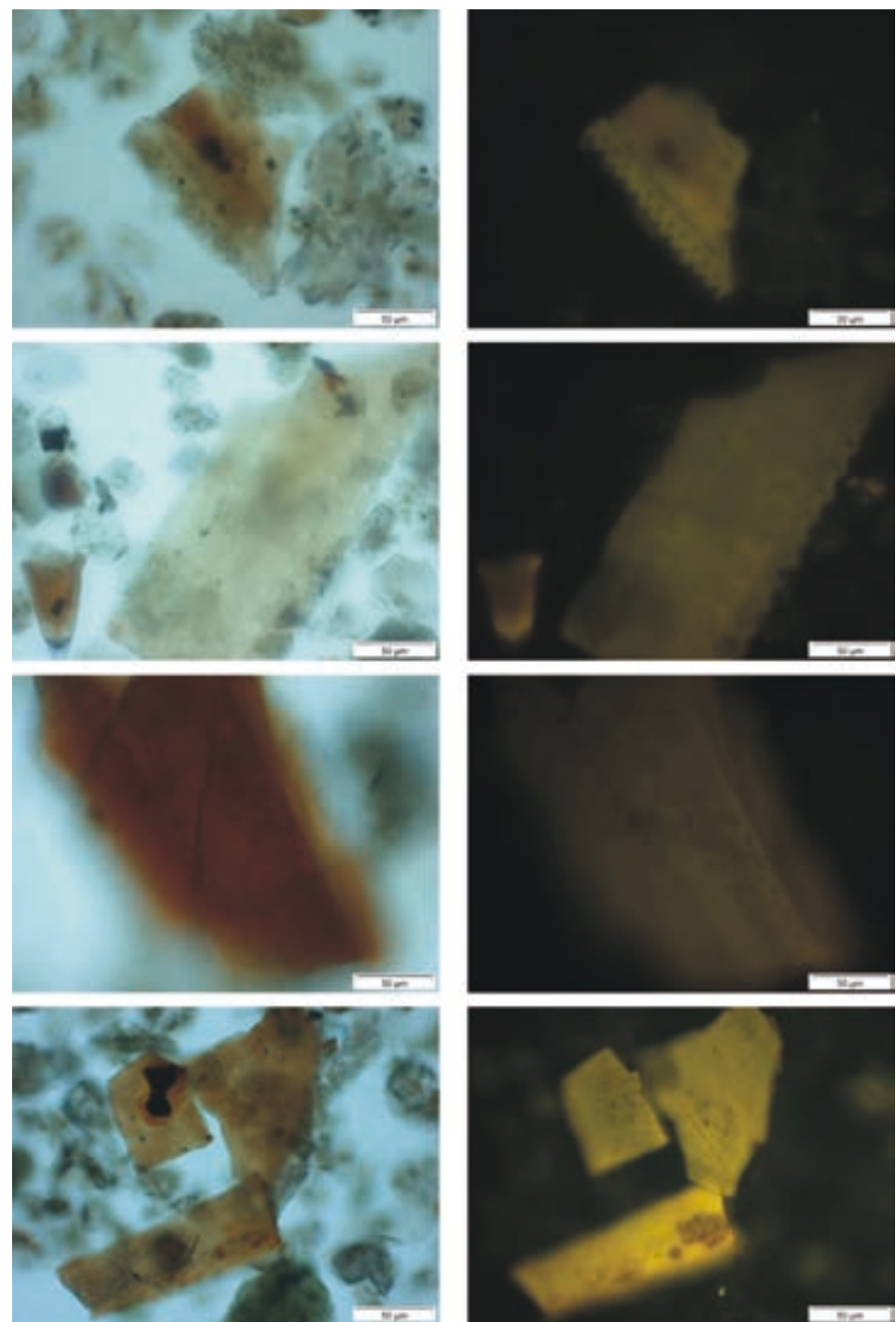

Fig. 2 - Fragmentos de carapaça de Cyzicus pricei; reparar na ornamentação carenada microalveolar, em luz branca (direita) e fluorescência (esquerda) 

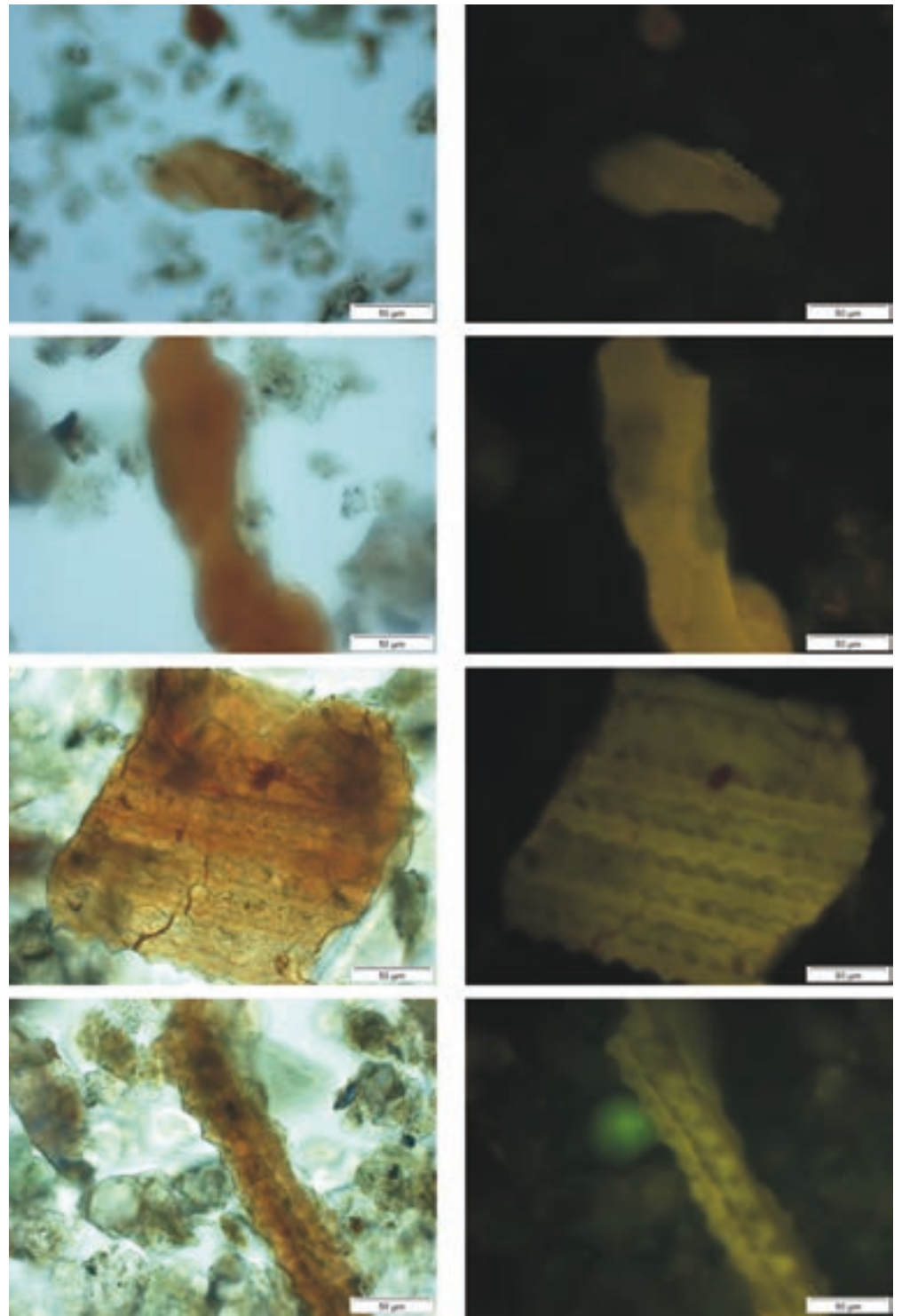

Fig. 3 - Fragmentos de carapaça de Cyzicus pricei; reparar na ornamentaçâo carenada microalveolar, em luz branca (direita) e fluorescência (esquerda). 